Please do not remove this page

RMIT

UNIVERSITY

\title{
Acoustic properties of a porous polycarbonate material produced by additive manufacturing
}

Liu, Zhengqing; Zhan, Jiaxing; Fard, Mohammad; Davy, John

https://researchrepository.rmit.edu.au/esploro/outputs/9921860375201341/filesAndLinks?institution=61RMIT_INST\&index=null

Liu, Z., Zhan, J., Fard, M., \& Davy, J. (2016). Acoustic properties of a porous polycarbonate material produced by additive manufacturing. Materials Letters, 181, 296-299.

https://doi.org/10.1016/j.matlet.2016.06.045

Document Version: Accepted Manuscript

Published Version: https://doi.org/10.1016/j.matlet.2016.06.045

Repository homepage: https://researchrepository.rmit.edu.au

(c) 2016 Elsevier B.V. All rights reserved.

Downloaded On 2023/04/26 21:44:24 +1000

Please do not remove this page 
Thank you for downloading this document from the RMIT Research Repository.

The RMIT Research Repository is an open access database showcasing the research outputs of RMIT University researchers.

RMIT Research Repository: http://researchbank.rmit.edu.au/

\section{Citation: \\ Liu, Z, Zhan, J, Fard, M and Davy, J 2016, 'Acoustic properties of a porous polycarbonate material produced by additive manufacturing', Materials Letters, vol. 181, pp. 296-299.}

See this record in the RMIT Research Repository at:

https://researchbank.rmit.edu.au/view/rmit:37205

Version: Accepted Manuscript

\section{Copyright Statement:}

(C) 2016 Elsevier B.V. All rights reserved.

(C) 2016. This manuscript version is made available under the CC-BY-NC-ND 4.0 license http://creativecommons.org/licenses/by-nc-nd/4.0/

Link to Published Version:

https://dx.doi.org/10.1016/j.matlet.2016.06.045 


\title{
Acoustic properties of a porous polycarbonate material produced by additive manufacturing
}

\author{
Zhengqing Liu a, Jiaxing Zhan a,*, Mohammad Fard ${ }^{a, * *}$, John Laurence Davy ${ }^{\mathrm{b}}$ \\ a School of Engineering, RMIT University, Bundoora 3083, Australia \\ ${ }^{b}$ School of Science, RMIT University, Melbourne 3001, Australia \\ * Corresponding author. Tel.: +6139925 4136. \\ ** Corresponding author. Tel.: +61 409342986. \\ E-mail address: Jiaxing.Zhan@dtsysint.com (J. Zhan), mohammad.fard@rmit.edu.au (M. Fard).
}

\begin{abstract}
This paper aims to investigate the acoustic properties of porous polycarbonate material (PPM) fabricated by additive manufacturing, and the feasibility to tailor artificial porous sound absorbing material is studied. Four PPM samples with different perforation angles were printed by using a 3D printer. Polycarbonate material was used, and the samples were printed with 25.4 micrometre layer resolution. Their sound absorption coefficient was experimentally measured using the twomicrophone impedance tube method. It was found that with increased the perforation angle and constant porosity, the sound absorption was decreased. The results indicated that by adjusting the perforation angle and the airgap behind the sample, significant sound absorption can be achieved in the low frequencies where conventional porous materials may not be that effective. The results obtained in this paper provide a new approach for the fabrication of new porous sound absorbing materials.
\end{abstract}

Keywords: Porous polycarbonate material, Additive manufacturing, Perforation angle, Porosity, Impedance tube, Sound absorption coefficient

\section{Introduction}

Porous sound absorbing materials are widely used in the acoustic design of buildings, vehicles, ships, and aircraft. Porous material is popular for noise control because of the ease of use, the range of possible designs and flexible combinations, and the fact that no extra energy input is required. In order to reduce the environmental implications and human health issues associated with the use of conventional porous materials [1-3], the use of innovative porous materials for noise control is necessary, and they have been extensively investigated in the past few years.

Aiming at understanding the acoustic performance of porous fibrous materials and establishing a database, Wang and Torng [4] have experimentally investigated porous fibrous materials manufactured from glass fibre or mineral wool. Ersoy and Kucuk [5] characterized an industrial tealeaf-fibre waste material for its sound absorbing properties. Similarly, the acoustic properties of bioluffa-fibre were measured by Koruk and Genc [6]. Besides natural fibre materials, the acoustic sound absorption coefficient of open-cell polyolefin-based, poly (ethylene-co-octene) foam, and poroelastic porous foams were also examined [7-10]. Arenas et al. [11] designed an acoustic absorbing material for highway noise barriers using co-combustion bottom ash. The sound 
absorption characteristics of different porous metal materials were also quantified in the literature [12-16].

The acoustic properties of various porous materials created by different manufacturing methods were already studied and documented. However, so far, the sound absorption of porous polycarbonate material (PPM) produced by additive manufacturing has not been well presented in the literature [4-16]. This paper investigates the acoustic properties of 3D printed (3DP) PPM and the feasibility of the fabrication of the porous sound absorbing material by additive manufacturing.

\section{Material and methods}

\subsection{Materials and test samples}

The VisiJet-SL Materials (Clear), supplied by 3D-Systems/Australia (Australia), is used in this study. It consists of $50 \%$ propylene carbonate and $50 \%$ mixed triarylsulfonium salts, and the density is $1.12 \mathrm{~g} / \mathrm{cm}^{3}$. Four PPM samples, namely 3DP-1, 3DP-2, 3DP-3, and 3DP-4, are printed by using a professional 3D printer (ProJet 7000), which is purchased from 3D-System Inc. (USA). All samples are printed with 25.4 micrometre layer resolution; their accuracy is $0.0254-0.05 \mathrm{~mm}$ per $25.4 \mathrm{~mm}$ of part dimension. In this study, the model interior is defined as solid, the thickness and diameter of the samples are $10 \mathrm{~mm}$ and $29 \mathrm{~mm}$, and the pore diameter is $0.8 \mathrm{~mm}$ as shown in Fig.1. The perforation angle, $\theta$ of the 3DP-1, 3DP-2, 3DP-3 and 3DP-4 are $0^{\circ}, 15^{\circ}, 30^{\circ}$ and $45^{\circ}$, respectively. The samples had an average constant porosity $\sigma=7.4 \%$.

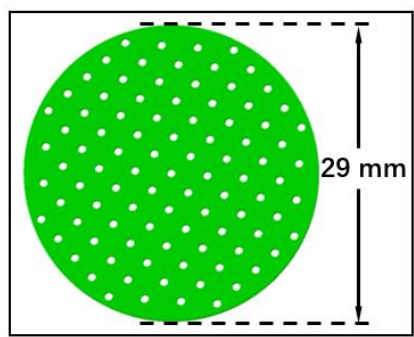

a)

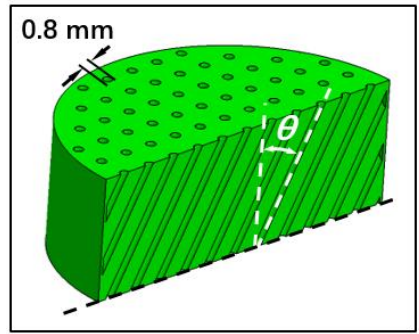

b)

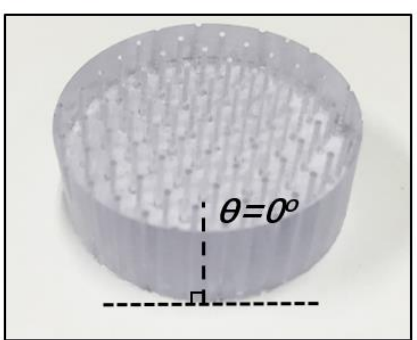

c)

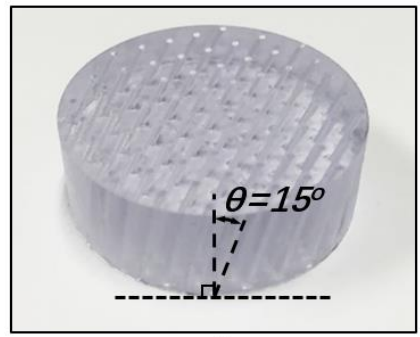

d)

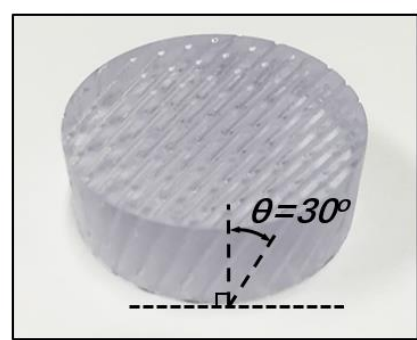

e)

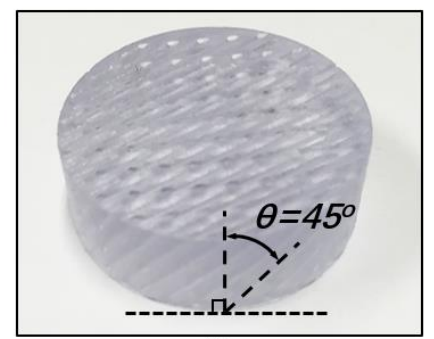

f)

Fig. 1. PPM samples: design of test samples (a) \& (b), 3DP-1 with $\theta=0^{\circ}(\mathrm{c}), 3 \mathrm{DP}-2$ with $\theta=15^{\circ}(\mathrm{d}), 3 \mathrm{DP}-3$ with $\theta=30^{\circ}(\mathrm{e})$ and 3DP-4 with $\theta=45^{\circ}(\mathrm{f})$.

\subsection{Sound absorption coefficient measurement}

Fig. 2 shows the measurement setup in the laboratory, where the Brüel \& Kjær impedance tube and Pulse LabShop are used in this study. The two-microphone transfer function method is used according to ASTM E1050-12 standard [17]. In this method, the complex sound reflection coefficient 
$R$ of a test sample is calculated from the corrected acoustic transfer function $H_{12}$. According to Chung and Blaser's [18] results, the complex sound reflection coefficient is:

$$
R=\frac{H_{12}-e^{-j k s}}{e^{j k s}-H_{12}} e^{2 j k(l+s)}
$$

where the wave number $k=2 \pi f / c, l$ is the distance between Mic 2 (Fig. 2) and the front of the test sample, $s$ is the distance between the two microphones. The specific impedance ratio $Z / \rho c$ and the normal incidence sound absorption coefficient $\alpha_{n}$ are then calculated by [17-19]:

$$
\begin{aligned}
& \frac{Z}{\rho c}=\frac{1+R}{1-R} \\
& \alpha_{n}=1-|R|^{2}
\end{aligned}
$$

where $\rho$ and $c$ are the density and speed of sound in the air, respectively. It should be noted that the normal sound absorption coefficient indicates the ability of the porous material to absorb sound energy in different frequency bands.

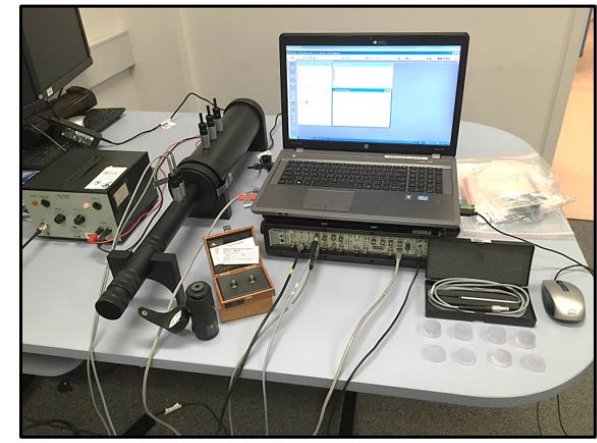

a)

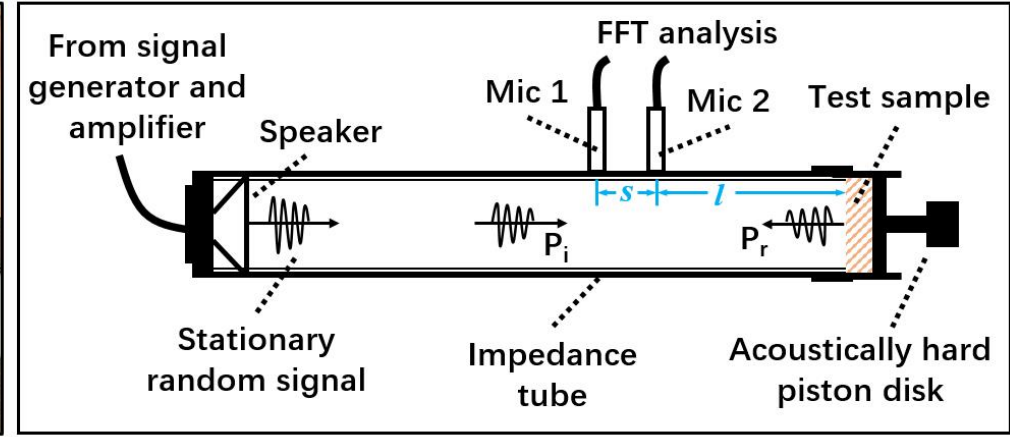

b)

Fig. 2. Acoustic sound absorption coefficient measurement: measurement setup in the laboratory (a) and schematic of two-microphone impedance tube method (b).

Furthermore, in order to understand the effect of an airgap on the sound absorption coefficient of PPM, the following two cases were investigated. One case had an airgap behind the samples in the impedance tube and the other had no airgap.

\section{Results and discussion}

The sound absorption coefficients of the PPM samples in the range from 500 to $6000 \mathrm{~Hz}$ are shown in Fig. 3. It can be seen that the sound absorption coefficient curves of the four PPM samples have a similar shape. The peaks of their sound absorption coefficients lie in the frequency range from $2000 \mathrm{~Hz}$ to $4000 \mathrm{~Hz}$. Note that the 3DP-1 with perforation angle $\theta=0^{\circ}$ has the highest sound absorption coefficient at the frequency of $3328 \mathrm{~Hz}$. The results show that the increase of the perforation angle gradually decreases the peak sound absorption coefficient of the PPM sample and 
its corresponding frequency. The sound absorption of the PPM sample with the largest perforation angle $\theta=45^{\circ}$ (3DP-4) is the poorest. The frequencies of the peaks of sound absorption coefficient of the PPM samples with no air cavity behind are lower than the quarter wave length resonant frequencies. There must have been a small air gap at the back of the samples. An increase of perforation angle lengthens the holes and thus decreases the resonant frequency at which maximum sound absorption occurs because the acoustical mass of the holes is increased. It should be noted that the peak sound absorption coefficient values at $1536 \mathrm{~Hz}$ and $4864 \mathrm{~Hz}$ are due to the inherent resonances of impedance tube.

a)

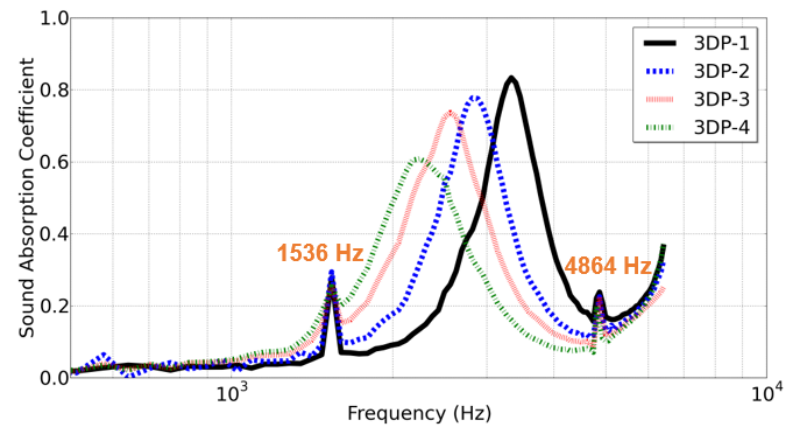

b)

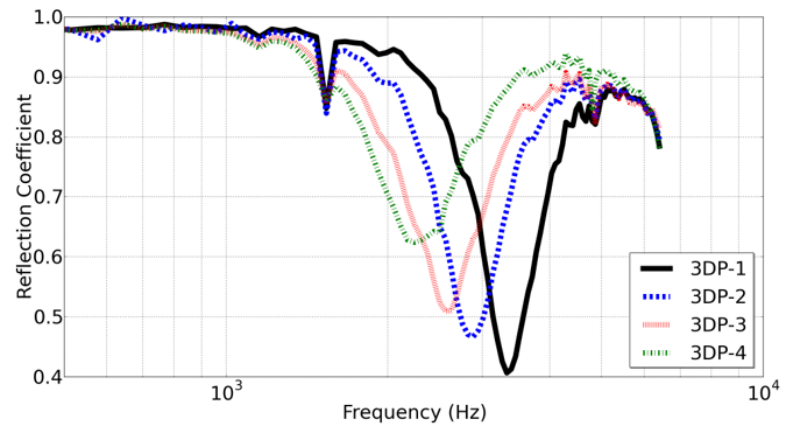

Fig. 3. Measurement results of PPM samples: sound absorption coefficient (a) and sound reflection coefficient (b).

a)

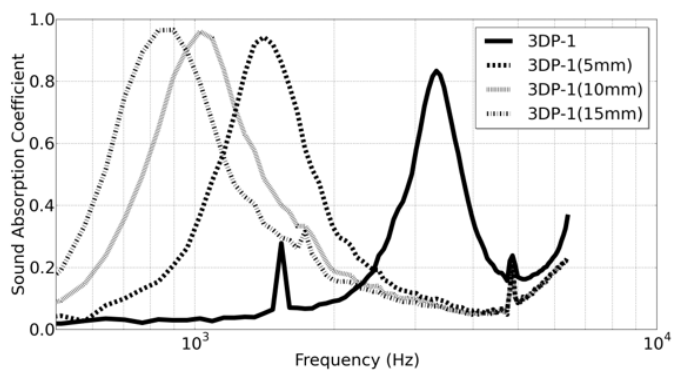

b)

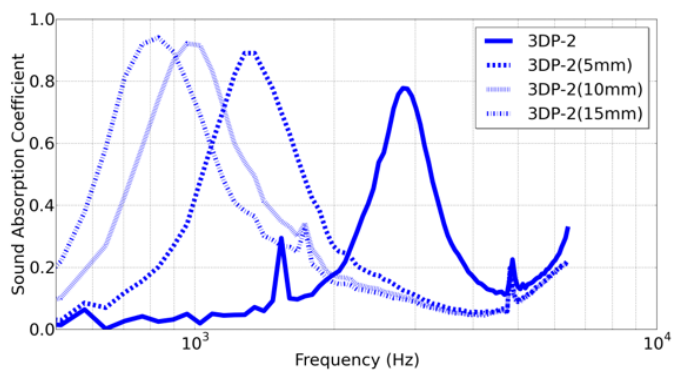

c)

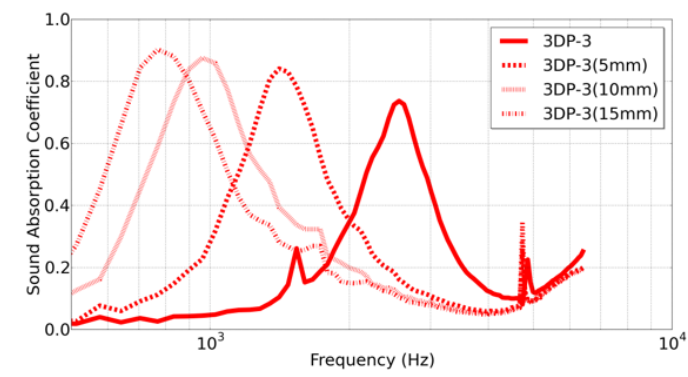

d)

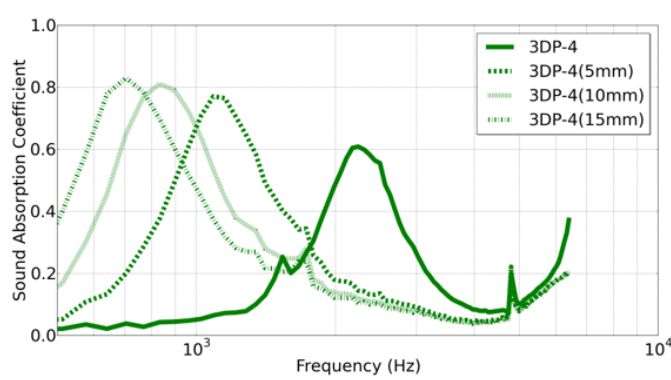

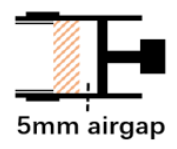

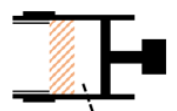

$10 \mathrm{~mm}$ airgap

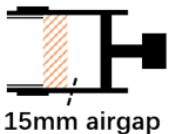

Fig. 4. Measurement results of PPM samples with different airgaps for: 3DP-1 (a), 3DP-2 (b), 3DP-3 (c) and 3DP-4 (d).

Fig. 4 summarizes the sound absorption coefficient of the PPM for the case of different airgaps $(5 \mathrm{~mm}, 10 \mathrm{~mm}$ and $15 \mathrm{~mm})$ behind the test samples in the impedance tube. Here, all sound absorption coefficient graphs, regardless of perforation angle, show a similar variation: the airgap substantially shifts the peak absorption coefficient toward the lower frequencies and improves the low frequency sound absorption. This is due to the holes, which are now open at both ends, acting as an acoustic mass and the air cavity acting as an acoustic spring which creates a mass-spring resonance. It is clear that the PPM samples can be tuned to have peak sound absorption at a 
particular frequency, by adjusting the perforation angle and the airgap behind the sample. However, the overall thickness and acoustic performance must be considered as design variables, in order to obtain the sound absorption coefficient peak in the desired frequency band.

\section{Conclusion}

In this study, a new method for preparing acoustic porous materials has been successfully developed by using additive manufacturing. The 3D printed PPM samples demonstrate excellent sound absorption at medium to low frequencies. The effects of perforation angle have been demonstrated. The results show that increasing the angle of the slanted pores decreases the sound absorption coefficient when the porosity is kept constant. The results indicate that the frequency of the corresponding peak value of sound absorption coefficient was reduced, with increasing airgap behind the test samples in the impedance tube. The results obtained in this paper can provide a new approach for the fabrication and investigation of porous materials. For instance, the appropriate design of perforation angle or combination with an airgap could improve the sound absorption coefficient in specific frequency bands providing the thickness and acoustic properties are considered. In future research emphasis will be given to improving the sound absorption coefficient through optimizing the model of the PPM. The presented approach can be extended to determine the effects of thickness and porosity of the PPM on its sound absorbing properties.

\section{Acknowledgements}

The authors would like to thank Excellerate Australia Ltd and Futuris Automotive Group (Australia) for their financial support in this research. The authors are also thankful to Mr. Andre Clemann, Mr. Mark Overend, Mr. Peter Tkatchyk and Mr. Patrick Wilkins for their technical support.

\section{References}

[1] P. Gle, E. Gourdon, L. Arnaud, Acoustical properties of materials made of vegetable particles with several scales of porosity, Appl. Acoust. 72 (2011) 249-259.

[2] F. Asdrubali, S. Schiavoni, K.V. Horoshenkov, A review of sustainable materialsfor acoustic applications, Buil. Acoust.19 (2012) 283-312.

[3] S.V. Joshi, L.T. Drzal, A.K. Mohanty, S. Arora, Are natural fiber composites environmentally superior to glass fiber reinforced composites?, Compos. Part A-Appl. Sci. Manuf. 35 (2004) 371-376.

[4] C.-N. Wang, J.-H. Torng, Experimental study of the absorption characteristics of some porous fibrous materials, Appl. Acoust. 62 (2001) 447-459.

[5] S. Ersoy, H. Küçük, Investigation of industrial tea-leaf-fibre waste material for its sound absorption properties, Appl. Acoust. 70 (2009) 215-220.

[6] H. Koruk, G. Genc, Investigation of the acoustic properties of bio luffa fiber and composite materials, Mater. Lett. 157 (2015) 166-168.

[7] M. Álvarez-Láinez, M.A. Rodríguez-Pérez, J.A. de Saja, Acoustic absorption coefficient of open-cell polyolefin-based foams, Mater. Lett. 121 (2014) 26-30.

[8] G. Wu, R. Li, Y. Yuan, L. Jiang, D. Sun, Sound absorption properties of ceramic hollow sphere structures with micro-sized open cell, Mater. Lett. 134 (2014) 268-271.

[9] P.W. Jones, N.J. Kessissoglou, Simplification of the Delany-Bazley approach for modelling the acoustic properties of a poroelastic foam, Appl. Acoust. 88 (2015) 146-152. 
[10] T. Zhao, M. Yang, H. Wu, S. Guo, X. Sun, W. Liang, Preparation of a new foam/film structure poly (ethylene-co-octene) foam materials and its sound absorption properties, Mater. Lett. 139 (2015) 275278.

[11] C. Arenas, C. Leiva, L.F. Vilches, H. Cifuentes, Use of co-combustion bottom ash to design an acoustic absorbing material for highway noise barriers, Waste. Manag. 33 (2013) 2316-2321.

[12] Z. Bo, C. Tianning, Calculation of sound absorption characteristics of porous sintered fiber metal, Appl. Acoust. 70 (2009) 337-346.

[13] D. Cuiyun, C. Guang, X. Xinbang, L. Peisheng, Sound absorption characteristics of a hightemperature sintering porous ceramic material, Appl. Acoust. 73 (2012) 865-871.

[14] J. Ru, B. Kong, Y. Liu, X. Wang, T. Fan, D. Zhang, Microstructure and sound absorption of porous copper prepared by resin curing and foaming method, Mater. Lett. 139 (2015) 318-321.

[15] P. Sun, Z. Guo, Preparation of steel slag porous sound-absorbing material using coal powder as pore former, J. Environ. Sci. 36 (2015) 67-75.

[16] P. Sun, Z. Guo, Sintering preparation of porous sound-absorbing materials from steel slag, Trans. Nonferrous Met. Soc. China. 25 (2015) 2230-2240.

[17] ASTM E 1050-12, Standard Test Method for Impedance and Absorption of Acoustical Materials Using a Tube, Two Microphones and a Digital Frequency Analysis System, American National Standards Institution, New York, 2012.

[18] J.Y. Chung, D.A. Blaser, Transfer function method of measuring in-duct acoustic properties. I. Theory, J. Acous. Soc. Am. 68 (1980) 907-913.

[19] H. Koruk, An assessment on the performance of impedance tube method, Noise. Contr. Eng. J. 62 (2014) 264-274. 